Review Paper:

\title{
Nickel Sensitivity in Children Due to Using Stainless Steel Crowns: A Narrative Review
}

\author{
Ali Malekzadeh Shafaroudi ${ }^{1}$ (D) Pegah Nasiri $^{1}$ (D), Azam Nahvi' ${ }^{2,3^{*}}$ (D)
}

1. Student Research Committee, Faculty of Dentistry, Mazandaran University of Medical Sciences, Sari, Iran.

2. Dental Research Center, Mazandaran University of Medical Sciences, Sari, Iran.

3. Department of Pediatric Dentistry, Faculty of Dentistry, Mazandaran University of Medical Sciences, Sari, Iran.

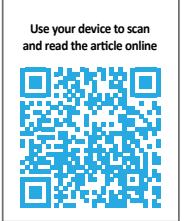

Citation Malekzadeh Shafaroudi A, Nasiri P, Nahvi A. Nickel Sensitivity in Children Due to Using Stainless Steel Crowns: A Narrative Review. Journal of Pediatrics Review. 2021; 9(2):145-152. http://dx.doi.org/10.32598/jpr.9.2.870.2

http://dx.doi.org/10.32598/jpr.9.2.870.2

Article info:

Received: 27 Sep 2020

First Revision: 20 Oct 2020

Accepted: 18 Nov 2020

Published: 01 April 2021
Keywords:

Nickel, Allergy, Stainless steel crown, Children

\begin{abstract}
A B STR A C T
Context: Stainless Steel Crowns (SSC) are stable and durable restorations and a valuable technique in repairing deciduous teeth with extensive caries. Nickel and chromium are the main composing elements of SSCs, i.e. released in the oral environment; they can cause allergic reactions, especially in nickel-sensitive children. The symptoms of these reactions include gingival edema and the loss of alveolar bone.
\end{abstract}

Evidence Acquisition: The required data used in our review were searched from articles published until 2020 and collected from online databases, including Scopus, PubMed, Google Scholar, and Science Direct, using "Nickel, Allergy, and SSCs" keywords. Articles concerning SSCS and their application, nickel allergy released from crowns, and their symptoms were included in this study. After the abstract screening, we recalled relevant studies for full-text review.

Results: We are exposed to nickel every day in various forms; some individuals present hypersensitivity reactions when exposed to the slightest amounts of this metal. Nickel is a base metal and among the elements used in SSCs. Nickel is released from SSCs during the corrosion process in the oral environment. Excessively released nickel ions cause chronic fatigue syndrome, sensitive lymph nodes, muscle aches, and headaches.

Conclusions: The amount of nickel released from SSCs is less than the number of other sources; thus, the immunological reactions of a large percentage of the population to this excess amount of nickel ions in the bloodstream are normal and cause no severe problems. 


\section{Context}

espite advances in community health, dental caries remains a serious health issue worldwide (1). Treating caries in children varies depending on the size of the lesion and the child's behavior. Among restorative materials used in pediatric dentistry, Stainless Steel Crowns (SSC), or prefabricated metal crowns can provide a definitive restoration for primary molars (2). SSCs were first introduced to pediatric dentistry by Humphrey in 1950. These restorations are durable, resistant to darkening, and have little technical sensitivity during placement. Besides, they are a valuable restorative technique for the treatment of decayed deciduous teeth, i.e. superior and durable over multilevel amalgam restorations and other restorations when restoring deciduous teeth (3). These crowns present numerous advantages, like a relative lack of sensitivity to saliva during placement (4).

The chemical composition of SSC is similar to numerous orthodontic braces and wires, including 65\%-75\% iron, $17 \%-20 \%$ chromium, $13 \%-18 \%$ nickel, and $<2 \%$ manganese, silicon, and carbon (5). The widespread use of SSCs in dentistry is due to their desirable mechanical properties, high strength, favorable biocompatibility, cost-effectiveness, and good corrosion resistance (6). An element released from SSC is nickel, i.e. a solid, silver-white, malleable metal with an atomic number of 28 (7). Adding nickel and chromium to stainless steel increases corrosion resistance (6). Nickel causes allergies in almost $10 \%$ of the population and was identified as a mutagenic and carcinogenic agent in some studies (8, $9)$. The longer stainless steel metals are exposed to saliva and the oral environment, the more nickel ions will be released (10). The amount of nickel in dental alloys varies from very low to $>60 \%$ (11).

Studies suggested that the average prevalence of nickel allergy in Eastern Europe and North America is approximately $8.6 \%(0.7 \%-27.8 \%)$; it is more prevalent in females (12). Investigations also indicated that 1.1. Millions of American children are potentially allergic to nickel (13). It has also been reported that $8 \%$ to $10 \%$ of children and adolescence in the European general population present nickel allergy (14); however, this prevalence was about $23.7 \%$ in the children of North America between 1994 to 2014 (15). Nickel ion is a common cause of contact allergies and hypersensitivity reactions (16). Nickel released from appliances, like orthodontic braces causes allergic reactions and reduces the strength of appliances (17). The symptoms of an allergic reaction to nickel-containing alloys include inflamed hyperplastic gum tissue around the crown or space-maintainer; the loss of alveolar bone; as well as the edema of the gums, palate, and throat (11).

Many studies have evaluated the release of nickel ions from orthodontic brackets. However, given the widespread use of SSCs in pediatric dentistry, little is known about the release of nickel from such restorations; accordingly, concerns remain about the biological effects of this release $(18,19)$. Our study aimed to review the previous studies on nickel allergy. We also intended to provide appropriate information to dentists and specialists about this allergy in children and suggested methods to manage and reduce nickel sensitivity-induced damages.

\section{Evidence Acquisition}

Sources and search strategy: the required data were extracted from articles published until September 2020 using "Nickel, allergy, and SSCs" keywords, collected from online databases (Scopus, PubMed, Google Scholar, \& Science direct) and documents published from different international institutions until 15 September 2020. The search was restricted to articles published in English and Persian languages. Topics discussed in this review were as follows: the indications of SSCS, SSCs components, Nickel, and its use in dentistry, allergy, and management methods to nickel. After the abstract screening, the full text of the related studies was reviewed. The following types of studies were excluded from this review: in vitro studies, animal studies, studies published in languages other than English and Persian, case reports, narrative reviews, medical record reviews, meeting abstracts, historical articles, editorials, letter-to-editors, and commentaries. The included studies concerned those in which authors published information on SSCs and their application, nickel allergy released from crowns, and their symptoms.

\section{Results and Discussion}

\section{Carries and its complications}

Caries is the most frequent chronic disease in children that lack proper and timely treatment; this condition results in the loss of deciduous teeth before the time of permanent teeth eruption $(20,21)$. The premature loss of deciduous teeth can disrupt the balance of the neuromuscular system of the oral cavity, chewing, and beauty (22). 


\section{Treating caries in deciduous teeth}

SSCs are used to repair all posterior teeth of young patients with a high risk of caries and multiple proximal lesions. Otherwise, these teeth are restored with amalgam or cosmetic restorations (23).

SSCS

SSCs, also known as prefabricated metal crowns (23), is the most effective and durable restorations for maintaining deciduous molars. Some retrospective studies have compared the durability of SSCs with amalgam restorations. Accordingly, they all have demonstrated the superiority of SSC over multilevel amalgam restorations (24). These crowns are used as selective restorations in cases, like restoring deciduous teeth following pulpotomy or pulpectomy, restoring broken deciduous molars, and for the protection of teeth that have lost large structures (25).

\section{Nickel}

Nickel is an element in row 4 and group 2 of the periodic table, with a melting point of $1455^{\circ} \mathrm{C}$. Nickel is cheaper than precious metals, such as silver, gold, platinum, and palladium; therefore, nickel and its alloys are extensively used in the manufacture of dental appliances. In dental alloys, nickel is usually alloyed with 4 other conductive metals as well as several other metals, and to a lesser extent with non-metals. Nickel is a base metal. In other words, its reactivity with other elements is high, compared to noble metals $(26,27)$.

The highest amount of human exposure to nickel is through diet, the average exposure to which ranges between 200 and $600 \mu \mathrm{g} / \mathrm{d}$ through diet (28). The maximum amount of nickel in water is about $0.04 \mathrm{mg} / \mathrm{d}$. Serum nickel released from SSCs is below toxic levels but exceeds daily intake levels (29). The average nickel content of some nutrients is presented in Table 1. Nickel can also be found in medicines and vitamins. For example, each Acunol tablet prescribed to treat acne contains 0.5 mg of ionized nickel (30).

Nickel is added to stainless steel alloys to improve biochemical properties, such as durability and hardness, and to decrease the cost of the alloy. Nickel is essential for certain plants and animals. Nickel compounds are found everywhere. They are considered as a part of the usual diet in foods, like vegetables, and are among the main components of enzyme systems in humans (7).

\section{Applying nickel in dentistry}

In dentistry, most nickel-containing alloys are nickelbased, including stainless steel. Furthermore, they are used in orthodontic wires, brackets, crowns, as well as endodontic files and tools. Additionally, due to the high elastic modulus of nickel, compared to gold and palladium, nickel alloys are applied in the manufacture of dental prostheses (32). Nickel-Titanium alloys are widely used in orthodontic archwires. Besides, due to their suitable clinical function, these archwires are the first choice in orthodontic treatment (33).

Older generations of SSC had up to $72 \%$ nickel; however, the newer generations of SSC contain 12\%-9\% nickel. Nickel released from orthodontic appliances made of nickel-titanium and stainless steel, increases, then decreases during the first week after placement (16). Studies revealed that using 8 SSCs for deciduous teeth along with 4 space maintainers does not pose a risk of nickel toxicity to the child. However, it is better to take a patch test from the patient before selecting nickel-containing alloys; accordingly, an alternative alloy can be used if necessary (11).

\section{The release of nickel from dental alloys}

Although nickel alloys are used in dentistry, the corrosion process occurs in the oral environment due to biochemical conditions. For example, intraoral bacterial biofilm can decline the $\mathrm{pH}$ of the alloy surface and significantly increase corrosion and ion diffusion (34). Nickel is released from SSCs during corrosion. Among SSC corrosion products, the release of nickel and chromium ions has attracted more attention in studies. This could be due to their adverse effects, which include allergies, dermatitis, gingivitis, and damage to tooth enamel (35). Studies reported no association between the release of nickel ions and the nickel content of orthodontic wires; however, the same was correlated with the nature of the alloy and the method of the appliance manufacture (36). Studies highlighted that blood samples gathered from 31 individuals who underwent dental treatment presented no measurable accumulation of nickel, compared to pre-orthodontic nickel levels (8).

\section{Allergy to nickel-containing alloys}

Nickel allergy is a reaction that develops after the first, or a short, or repeated long-term contact with nickel or nickel-containing substances, depending on the individual's sensitivity. The degree of reaction also varies among individuals (37). Nickel allergy, in particular, is a 


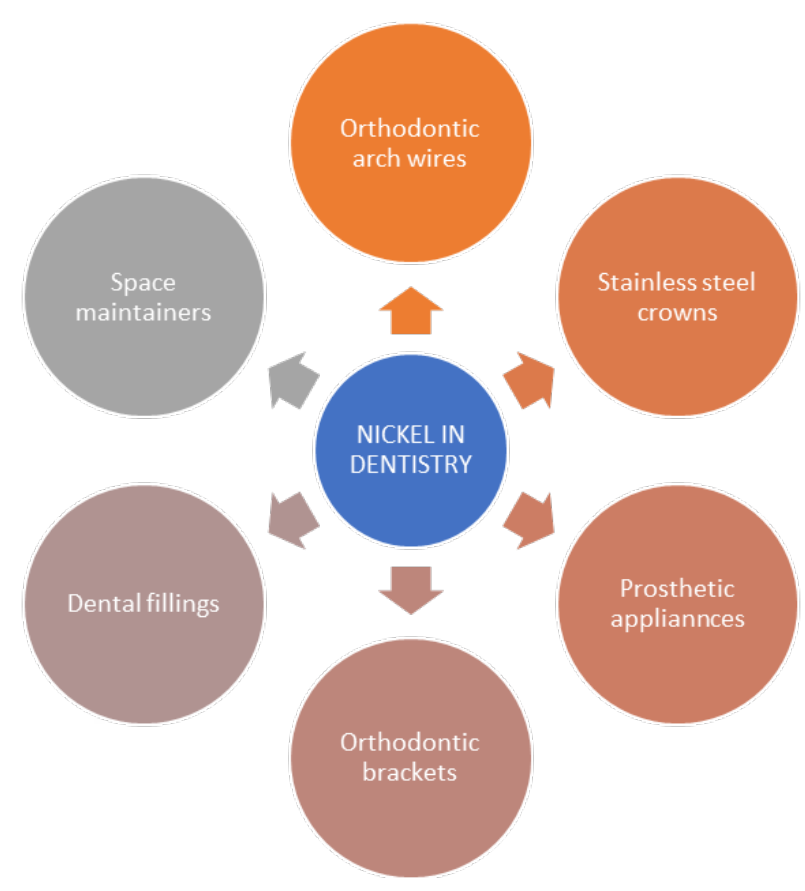

Figure 1. The application of nickel in dentistry

Journal of Pediatrics Review

contact allergy, i.e. an allergic skin reaction in response to contact with an allergen or a nickel-like stimulant. Nickel allergy can occur at any age and usually occurs as eczema a few days after the first contact, appearing as itchy, red, pigmented, dry, dry skin rashes with watery blisters. The affected area is usually limited to the contact area; however, it may appear in other parts of the body (38). Studies demonstrated that of the 391 children who underwent a patch test between 2001 and 2004 to test for nickel allergies, $28 \%$ tested positive (30).

The amount of nickel ions, i.e. enough to cause allergies varies from person to person. Temperature, $\mathrm{pH}$, scratches, the presence of other allergic conditions, race, gender, and age may be determinants that affect

Table 1. Mean nickel content of different types of food [31] the rate of nickel sensitivity (39). Few studies suggested that individuals with oral nickel allergy receive $>5000 \mu \mathrm{g}$ of nickel as a dose of a skin allergy reaction. A dose of 1-2 mg of intravenous nickel causes acute skin allergies in sensitive patients (40).

\section{The mechanism of allergy}

Allergic reactions are mediated by the immune system. In a sensitive person, allergic reactions can start with a small amount of allergen. For example, if nickel ions are released from a nickel-plated substance, allergies develop following direct and prolonged contact with the skin. The individual first becomes sensitive to the allergen (37). Subsequent exposures, if large enough, may

\begin{tabular}{ccc}
\hline Type of Food & Mean Nickel Content $(\mu \mathrm{g} / \mathrm{g})$ \\
\hline Cheese & 0.1 \\
\hline Fish & 0.04 \\
\hline Egg & 0.05 \\
\hline Apple & 0.01 \\
\hline Tea & 0.05 \\
\hline Coffee & 0.02 \\
\hline Canned fruits & 0.31 \\
\hline Cauliflower & 0.3 \\
\hline
\end{tabular}


cause an allergic reaction. Some allergens, i.e. studied in clinical dental studies include eugenol, mercury, nickel, chromium, cobalt, resin-based materials, and so on. Most dental allergies, including allergic reactions to nickel-containing alloys, arise from type IV hypersensitivity reactions induced by T lymphocytes (41). Allergies initiate at the age of 2-5 years and reach their maximum level in $10-15$ years (16).

The ability of a metal or alloy to cause allergic reactions depends on its corrosion pattern; the extent of corrosion in an alloy depends on the metal compounds of the alloy, the variables used to make the alloy, such as temperature and oral environment conditions, especially the $\mathrm{pH}$ of the alloy (7).

The mechanism currently understood from nickel allergy in humans is that $\mathrm{Ni}^{2+}$ is not antigenic by its self; however, nickel accumulations containing histidine or protein, bind to Langerhans cells. These cells, located in the basal layer of the epidermis, actively help regulate and monitor skin immunity. Furthermore, they are responsible for antigen processing and antigen delivery to lymphocyte cells. Langerhans cells are transported to regional lymph nodes, antigen processing takes place, and eventually, a population of altered T-lymphocytes is formed and translocated and may to even enter peripheral tissues, including the skin. At this stage, the subject becomes allergic. In an individual with hyper-sensitivity, when specific T-lymphocytes are exposed to the antigen, they release lymphokines; these are proteins that cause widespread action in other cells, including macrophagestimulating cells and the natural killer cell. These actions in inflamed tissues and other allergic responses try to destroy the foreign body. This integrated response is a factor that causes allergic dermatitis (42). Nickel allergy is a contact allergy, in which an allergic skin reaction occurs in response to exposure to a contact allergen or a stimulant, like nickel. Nickel allergy can occur at any age, usually within a few days after the first contact, in the form of eczema (allergic contact dermatitis). Besides, it is an itchy, scaly, rough, red, pigmented skin rash with juicy blisters (38). The reaction of hypersensitivity to metals is observed in $10 \%$ to $15 \%$ of the population and its prevalence is higher in women (10\%) than men (2\%) (42).

\section{The clinical signs of allergy}

Excessively released nickel ions cause CFS (chronic fatigue syndrome), tracheal ulcers, sensitive lymph nodes, muscle aches, headaches, insomnia, food allergies, odor sensitivity, noise, light, miscellaneous foods, severe periodontitis, gastrointestinal disorders, and other un- known diseases (38). Clinical signs attributed to nickel include allergic dermatitis, asthma, and mucosal ulcers, and at the cellular level, toxicity along with altered cell function (43). The clinical signs of nickel allergy in the oral cavity also include inflamed hyperplastic gingival tissue around the restoration or space maintainer, alveolar bone loss, and gingival edema (11).

\section{The diagnosis of nickel allergy}

Patch-test (on the upper back area) is mainly used to diagnose this type of allergy; however, other examinations, such as macrophage migration tests and lymphocyte transformation tests can also be employed. For patch-testing, in Europe, patches containing $2 \mathrm{mg}$ of nickel sulfate ( $5 \%$ nickel sulfate) per square centimeter, and in North America, patches containing 2.5\% nickel sulfate, are implemented. It is recommended to check for allergic reactions several times during the second, fourth, and seventh days after allergen exposure (14). Some groups, including children, present severe hypersensitivity reactions to even small amounts of nickel ions. If these populations are identified by nickel sensitivity tests in the early stages, alternative dental treatment approaches could be used.

\section{Conclusion}

We are exposed to allergens, like nickel every day in various forms. One example is the entry of nickel in dental restorations into the bloodstream through a corrosion reaction. The threshold of tolerance to nickel differs in various populations. The amount of nickel released from SSCs is less than the number of other sources; thus, the immunological reactions of a large percentage of the population to this excess level of nickel ions in the bloodstream cause no severe problems.

\section{Ethical Considerations}

\section{Compliance with ethical guidelines}

There were no ethical considerations to be considered in this research.

\section{Funding}

This research did not receive any grant from funding agencies in the public, commercial, or non-profit sectors. 


\section{Authors' contributions}

Conceptualization and supervision: Azam Nahvi and Pegah Nasiri; Methodology: Pegah Nasiri; Investigation, writing original draft : All authors; Writing - review \& editing: Ali Malekzadeh Shafaroudi; Supervision: Azam Nahvi, Ali Malekzadeh Shafaroudi.

\section{Conflicts of interest}

The authors declared no conflicts of interest.

\section{Acknowledgments}

The authors would like to thank the Deputy Director-General of Research and Technology of Mazandaran University of Medical Sciences and the Student Research Committee of the Faculty of Dentistry.

\section{References}

1. Petersen PE, Lennon MA. Effective use of fluorides for the prevention of dental caries in the $21^{\text {st }}$ century: The WHO approach. Community Dentistry and Oral Epidemiology. 2004; 32(5):319-21. [DOI:10.1111/j.16000528.2004.00175.x] [PMID]

2. Colak H, Dülgergil CT, Dalli M, Hamidi MM. Early childhood caries update: A review of causes, diagnoses, and treatments. Journal of Natural Science, Biology, and Medicine. 2013; 4(1):29-38. [DOI:10.4103/0976-9668.107257] [PMID] [PMCID]

3. Menek N, Başaran S, Karaman Y, Ceylan G, Şen Tunç E. Investigation of nickel ion release from stainless steel crowns by square wave voltammetry. International Journal of Electrochemical Science. 2012; 7:6465-71. https://d1wqtxts1xzle7.cloudfront.net/42453922/Investigation_of_Nickel_ lon_Release_from

4. Arab-Nozari M, Shokrzadeh M, Zamehran N, Yazdani Charati J, Nahvi A. Trimming and $\mathrm{pH}$ effects on nickel ion release from stainless steel crowns of primary teeth. Journal of Dentistry Indonesia. 2020; 27(3):125-30. [DOI:10.14693/ jdi.v27i3.1135]

5. Danaei SM, Safavi A, Roeinpeikar SMM, Oshagh M, Iranpour $\mathrm{S}$, Omidekhoda $\mathrm{M}$. Ion release from orthodontic brackets in 3 mouthwashes: An in-vitro study. American Journal of Orthodontics and Dentofacial Orthopedics. 2011; 139(6):730-4. [DOI:10.1016/j.ajodo.2011.03.004] [PMID]

6. Oh KT, Choo SU, Kim KM, Kim KN. A stainless steel bracket for orthodontic application. European Journal of Orthodontics. 2005; 27(3):237-44. [DOI:10.1093/ejo/cji005] [PMID]
7. Setcos JC, Babaei-Mahani A, Silvio LD, Mjör IA, Wilson NHF. The safety of nickel containing dental alloys. Dental Materials. 2006; 22(12):1163-8. [DOI:10.1016/j.dental.2005.11.033] [PMID]

8. Bishara SE, Barrett RD, Selim MI. Biodegradation of orthodontic appliances. Part II. Changes in the blood level of nickel. American Journal of Orthodontics and Dentofacial Orthopedics. 1993; 103(2):115-9. [DOI:10.1016/S08895406(95)70073-0] [PMID]

9. Mikulewicz M, Chojnacka K. Release of metal ions from orthodontic appliances by in vitro studies: A systematic literature review. Biological Trace Element Research. 2011; 139(3):241-56. [DOI:10.1007/s12011-010-8670-9] [PMID]

10. Karlina I, Amtha R, Roeslan BO, Zen Y. The Release of Total Metal Ion and Genotoxicity of Stainless Steel Brackets: Experimental Study Using Micronucleus Assay. The Indonesian Biomedical Journal. 2016; 8(2):97-102. [DOI:10.18585/ inabj.v8i2.193]

11. Kulkarni P, Agrawal S, Bansal A, Jain A, Tiwari U, Anand A. Assessment of nickel release from various dental appliances used routinely in pediatric dentistry. Indian Journal of Dentistry. 2016; 7(2):81. [DOI:10.4103/0975-962X.184649] [PMID] [PMCID]

12. Schuttelaar MLA, Ofenloch RF, Bruze M, Cazzaniga S, Elsner $\mathrm{P}$, Gonçalo $\mathrm{M}$, et al. Prevalence of contact allergy to metals in the European general population with a focus on nickel and piercings: The EDEN fragrance study. Contact Dermatitis. 2018; 79(1):1-9. [DOI:10.1111/cod.12983] [PMID] [PMCID]

13. Silverberg NB, Pelletier JL, Jacob SE, Schneider LC. Nicke allergic contact dermatitis: Identification, treatment, and prevention. Pediatrics. 2020; 145(5):1-13. [DOI:10.1542/ peds.2020-0628] [PMID]

14. Ahlström MG, Thyssen JP, Wennervaldt M, Menné T, Johansen JD. Nickel allergy and allergic contact dermatitis: A clinical review of immunology, epidemiology, exposure and treatment. Contact Dermatitis. 2019; 81(4):227-41. [DOI:10.1111/cod.13327] [PMID]

15. Warshaw EM, Aschenbeck KA, DeKoven JG, Maibach $\mathrm{HI}$ Taylor JS, Sasseville D, et al. Epidemiology of pediatric nicke sensitivity: Retrospective review of North American Contact Dermatitis Group (NACDG) data 1994-2014. Journal of the American Academy of Dermatology. 2018; 79(4):664-71. [DOI:10.1016/j.jaad.2018.02.071] [PMID]

16. Keinan D, Mass E, Zilberman U. Absorption of nickel, chromium, and iron by the root surface of primary molars covered with stainless steel crowns. International Journal of Dentistry. 2010; 2010:1-4. [DOI:10.1155/2010/326124] [PMID] [PMCID]

17. Mohamed AA-E, Ahmed AM, Mahmoud TT. Comparison between nickel and chromium levels in saliva of children having space maintainers versus stainless steel crowns (comparative study). International Journal of Science and Research. 2016; 5(2):663-6. [DOI:10.21275/v5i2.NOV161205] 
18. Schiff N, Grosgogeat B, Lissac M, Dalard F. Influence of fluoridated mouthwashes on corrosion resistance of orthodontics wires. Biomaterials. 2004; 25(19):4535-42. [DOI:10.1016/j.biomaterials.2003.11.042] [PMID]

19. Tahmasbi S, Ghorbani M, Masudrad M. Galvanic corrosion of and ion release from various orthodontic brackets and wires in a fluoride-containing mouthwash. Journal of Dental Research, Dental Clinics, Dental Prospects. 2015; 9(3):159-65. [DOI:10.15171/joddd.2015.030] [PMID] [PMCID]

20. Emadian M, Malekzadeh Shafaroudi A, Mesgarani A, Afkhaminia F, Nahvi A. Mother's knowledge regarding oral health among their preschool children. International Journal of Pediatrics. 2020; 8(8):11681-9. http:// ijp.mums.ac.ir

21. Nahvi A, Mesgarani A. Early childhood caries and its prevention. Clinical Excellence. 2020; 10(2):10-21. http:// ce.mazums.ac.ir/article-1-519-en.pdf

22. Kim Seow W. Environmental, maternal, and child factors which contribute to early childhood caries: A unifying conceptual model. International Journal of Paediatric Dentistry. 2012; 22(3):157-68. [DOI:10.1111/ j.1365-263X.2011.01186.x] [PMID]

23. Farahbakhshpoor F, Ghafournia M. A review of the efficacy of stainless steel crowns in the restoration of primary molars. Journal of Isfahan Dental School. 2012; 8(2):172-82. https://www.semanticscholar.org/paper/A-REVIEW-OFTHE-EFFICACY-OF-STAINLESS-STEEL-CROWNS-FatemehMaryam/aa9a764c24b1db14006395912249d1a2cb71ff57

24. Basir L, Shamsaei M, Ziaei S, Ziaei SA. Basir L, Shamsaei M, Ziaei SA. Evaluation of nickel releasing from stainless steel crowns regarding to "trimming": An in vitro study. Journal of the Indian Society of Pedodontics \& Preventive Dentistry. 2018; 36(1):58-64. [DOI:10.4103/JISPPD.JISPPD_33_17] [PMID]

25. Dimitrov E, Georgieva M, Andreeva R. Indications for use of performed crowns in pediatric dentistry. Medinform. 2016; 2:439-45. [DOI:10.18044/Medinform.201632.439]

26. Wataha JC. Alloys for prosthodontic restorations. The Journal of Prosthetic Dentistry. 2002; 87(4):351-63. [DOI:10.1067/mpr.2002.123817] [PMID]

27. Wataha JC, Shor K. Palladium alloys for biomedical devices. Expert Review of Medical Devices. 2010; 7(4):489-501. [DOI:10.1586/erd.10.25] [PMID]

28. Yassaei S, Dadfarnia S, Ahadian H, Moradi F. Nickel and chromium levels in the saliva of patients with fixed orthodontic appliances. Orthodontics: The Art \& Practice of Dentofacial Enhancement. 2013; 14(1):e76-81. [DOI:10.11607/ ortho.810] [PMID]

29. Beltagy TM. Effect of multiple stainless steel crowns on salivary $\mathrm{pH}$, nickel, and chromium levels. Egyptian Dental Journal. 2020; 66(1):1-16. [DOI:10.21608/edj.2020.77494]

30. Kornik R, Zug KA. Nickel. Dermatitis. 2008; 19(1):3-8. [DOI:10.2310/6620.2008.07082] [PMID]
31. Flyvholm MA, Nielsen GD, Andersen A. Nickel content of food and estimation of dietary intake. Zeitschrift für Lebensmittel-Untersuchung und -Forschung. 1984; 179(6):427-31. [DOI:10.1007/BF01043419] [PMID]

32. Wataha JC, Drury JL, Chung WO. Nickel alloys in the oral environment. Expert Review of Medical Devices. 2013; 10(4):519-39. [DOI:10.1586/17434440.2013.811868] [PMID]

33. D’Antò V, Valletta R, Amato M, Schweikl H, Simeone M, Paduano $S$, et al. Effect of nickel chloride on cell proliferation. The Open Dentistry Journal. 2012; 6:177-81. [DOI:10.2174/ 1874210601206010177] [PMID] [PMCID]

34. Wataha JC, Lockwood PE, Messer RLW, Lewis JB, Mettenburg DJ. Brushing-induced surface roughness of nickel-, palladium-, and gold-based dental casting alloys. The Journal of Prosthetic Dentistry. 2008; 99(6):455-60. [DOI:10.1016/ S0022-3913(08)60107-9]

35. Schmalz G, Garhammer P. Biological interactions of dental cast alloys with oral tissues. Dental Materials. 2002; 18(5):396-406. [DOI:10.1016/S0109-5641(01)00063-X]

36. Grimsdottir MR, Gjerdet NR, Hensten-Pettersen A. Composition and in vitro corrosion of orthodontic appliances. American Journal of Orthodontics and Dentofacial Orthopedics. 1992; 101(6):525-32. [DOI:10.1016/0889-5406(92)70127-V]

37. Hannah J. Nickel allergy: What it is and how it can affect our patient care. Gastroenterology Nursing. 2012; 35(4):263-8. [DOI:10.1097/SGA.0b013e3182603090] [PMID]

38. Gagneja M. In vitro analysis of nickel ion release from stainless steel for preformed crowns [Certificate of Advanced Specialty Program]. Portland, Oregon: Oregon Health \& Science University; 2007. [DOIP:10.6083/M4PG1PRC]

39. Wataha JC, Lockwood PE, Mettenburg D, Bouillaguet S Toothbrushing causes elemental release from dental casting alloys over extended intervals. Journal of Biomedical Materials Research Part B: Applied Biomaterials. 2003; 65B(1):180-5. [DOI:10.1002/jbm.b.10557] [PMID]

40. Oller AR. Respiratory carcinogenicity assessment of soluble nickel compounds. Environmental Health Perspectives. 2002; 110(suppl 5):841-4. [DOI:10.1289/ehp.02110s5841] [PMID] [PMCID]

41. Sunderman Jr FW, Hopfer SM, Sweeney KR, Marcus AH, Most BM, Creason J. Nickel absorption and kinetics in human volunteers. Proceedings of the Society for Experimental Biology and Medicine. 1989; 191(1):5-11. [DOI:10.3181/00379727-191-42881] [PMID]

42. Saito M, Arakaki R, Yamada A, Tsunematsu T, Kudo Y, Ishimaru N. Molecular mechanisms of nickel allergy. International Journal of Molecular Sciences. 2016; 17(2):202. [DOI:10.3390/ijms17020202] [PMID] [PMCID]

43. Burrows D. Hypersensitivity to mercury, nickel and chromium in relation to dental materials. International Dental Journal. 1986; 36(1):30-4. [PMID] 
This Page Intentionally Left Blank 